\title{
Making of epistemologically sophisticated physics teachers: A cross-sequential study of epistemological progression from preservice to in-service teachers
}

\author{
Lin Ding ${ }^{1, *}$ and Ping Zhang ${ }^{2, \dagger}$ \\ ${ }^{1}$ Department of Teaching and Learning, The Ohio State University, Columbus, Ohio 43210, USA \\ ${ }^{2}$ Department of Physics, Beijing Normal University, Beijing 100875, China
}

(Received 5 June 2016; published 2 November 2016)

\begin{abstract}
Previous literature on learners' epistemological beliefs about physics has almost exclusively focused on analysis of university classroom instruction and its effects on students' views. However, little is known about other populations or factors other than classroom instruction on learners' epistemologies. In this study, we used a cross-sequential method, combining both longitudinal and cross-sectional designs, to investigate an epistemological progression trend from preservice to in-service teachers. Six cohorts of participants were studied, who either were then attending or had completed an undergraduate teacher preparation program in physics at a major Chinese university. These cohorts were incoming freshmen, endof-year freshmen, end-of-year sophomores, end-of-year juniors, end-of-year seniors, and 1st-year high school physics teachers who were about to enter the 2 nd year of teaching. We used the Colorado Learning Attitudes about Science Survey (CLASS) as both a pretest and a post-test to gauge the changes in the participants' epistemological views over an entire academic year. Follow-up interviews were also conducted to explore factors responsible for such changes. Results showed that the epistemological trend as measured by CLASS did not increase monotonically. Instead, there was a decrease in the epistemological trend among the incoming freshmen in their first year undergraduate studies, followed by a long stasis until the end of the senior year. Then, there was a rebound for the end-of-year seniors in their 1 st year of teaching, followed by another plateau. Interviews revealed that the competitive learning environment, increased content difficulty, and unfamiliar pedagogies in college were major factors that negatively influenced incoming freshmen's views about physics. Conversely, a role change from student to teacher and relatively easy content in high school positively impacted end-of-year seniors' views about physics and learning.
\end{abstract}

DOI: 10.1103/PhysRevPhysEducRes.12.020137

\section{INTRODUCTION}

Physics instruction is often aimed at multiple goals. Besides content learning, sophisticated views about the nature of physics, or epistemology, and views about the nature of learning have also become an increasingly desirable outcome for many college-level courses [1-3]. The reason this topic has garnered great attention in the recent years is multifold, but in general it can be captured by the following two points. First, while teaching students physics content is unarguably a key focus of many physics classes [2-4], what actually outlives content and gets retained by most students 5 or 10 years after they leave class perhaps are their (hopefully appropriate) views about the nature of the subject and the learning of the subject. This is not to say that aiming for content learning does not

\footnotetext{
*Ding.65@osu.edu

tzhangping@bnu.edu.cn
}

Published by the American Physical Society under the terms of the Creative Commons Attribution 3.0 License. Further distribution of this work must maintain attribution to the author $(s)$ and the published article's title, journal citation, and DOI. need to be a long-term goal. Instead it is just the opposite, because sophisticated epistemological views in the long run can bolster content learning [3,4]. Seeking to increase the former, to a large extent, is an attempt to promote the latter. This argument inevitably leads to the second point regarding the relationship between epistemological beliefs and learning outcomes. A whole host of literature has shown that epistemological views can have a direct and causal impact on students' learning [5-7]. Learners who view physics as a body of disconnected bits and pieces and believe learning physics is merely accepting truth from authority are likely to approach the subject by rote memorization. On the other hand, those who view physics as a coherent body of interconnected concepts built by human construction tend to learn physics by sense making and conceptual reasoning. To this end, learners' epistemological views in every sense play a central role in physics education.

Research on students' views about physics and learning physics so far has largely focused on university students taking introductory physics courses [8]. Additionally, the students under investigation were mostly drawn from the higher institutions in American or European nations [9]. To date, very few studies have looked into learners' 
epistemological beliefs either before or after their attending university, and it is even more so for studies of Asian students, particularly those that probe the changes in Asian students' epistemological views across various stages of their academic or career lives.

In this study, we examine Chinese preservice and inservice teachers' epistemological beliefs about physics and their views about learning physics. Specifically, we use the Colorado Learning Attitudes about Science Survey (CLASS) [10] to investigate the changes in the participants' epistemological views at different stages of their undergraduate programs and beyond. The results of our study allow us to sketch out a trajectory extending from students just entering a preservice training program to teachers already in their in-service career.

Differing from the existing body of work, our empirical study contains several novel features. First is the unique population we chose to target, which is those either in their pathway to or already in their careers of teaching high school physics in China. This is an under-researched group of individuals but is such a group that directly participates in educating our next generation workforce. Therefore, studying their epistemological views holds great educational significance for future research and instructional development.

Another unique aspect of the current work is the use of the cross-sequential method [11] (see Sec. III for details), a method that combines the longitudinal design with the cross-sectional design to study participants at various academic stages. In our study, we recruited six cohorts of participants, ranging from incoming freshmen to 1st year in-service teachers who were about to start their 2nd year of teaching, and tracked them for an entire academic year. With a pretest of CLASS prior to the academic year and a post-test after the academic year, we produced both between-cohort cross-sectional differences and withincohort longitudinal changes. By piecing the two sets of results together, we can outline the epistemological progression from preservice to in-service teachers better than using only the cross-sectional design or the longitudinal design alone. In a sense, the cross-sequential method used in the study offers an accelerated version of the longitudinal design by linking small segments of repeated measurements across multiple cohorts at different academic stages (see Sec. III for details) [11].

A third unique facet of the study lies in the fact that we used the mixed methods approach [12], combing both quantitative surveys and qualitative interviews to uncover some hidden factors other than classroom instruction that may explain the changes in the participants' views about physics and learning (see Sec. III for details). Although a few previous studies [13-16] have reported epistemological variations among college students or postgraduates, none provided empirical explanations to account for such variations. In the current study, we first used the quantitative survey of CLASS to identify changes, if any, in the participants' views, and then followed with interviews to seek underlying mechanisms behind such changes. Because of the wide spread of our cohorts across different academic stages, the mixed-methods approach allows us to reveal factors other than classroom teaching that can affect an individual's epistemological views, hence adding new insight to the existing body of literature on this topic.

Since the overarching goal of the study is to explore the progression trend of participants' views about physics and learning physics from preservice to in-service teachers, we seek to answer the following specific research questions to address this goal:

(i) What does the overall progression trend of epistemological views about physics and learning physics as measured by CLASS look like for the participants at different stages of their professional lives, from the beginning of freshman year to the end of the 2nd year of teaching?

(ii) Where in their professional lives do participants show significant changes in their views about physics and learning physics as measured by CLASS?

(iii) What are some possible factors that may affect individuals' views about the nature of physics and learning physics?

In what follows, we first review important theoretical background on the topics of epistemological views and views about learning (Sec. II). Next, we describe the details of methodologies used in the study (Sec. III), followed by the analysis and findings we obtained from the surveys and interviews (Sec. IV). Finally, we discuss the conclusions and possible implications for future work (Sec. V).

\section{THEORETICAL FRAMEWORK}

\section{A. Epistemological beliefs}

From the traditional philosophy stance, epistemological beliefs are referred to as one's understandings about the nature of knowledge and the nature of knowing [16,17]. However, in the broader context of sociology, psychology, and pedagogy there appears to be no clear consensus on what counts as a definition for this construct or what dimensions should be subsumed under this construct [17-21]. For instance, educational researchers have argued that students' views about knowledge and knowing are closely intertwined with their beliefs about the nature of learning, and hence a priori artificial separation between the two may not yield practically useful interpretation [22]. On this matter, Elby [22], in his response to Hofer and Pintrich [17] and Sandoval [23,24], eloquently contended for more holistic investigations of learners' epistemological views that need to include the nature of knowledge and knowing as well as the nature of learning.

In the physics education research (PER) community, studies of students' epistemologies typically tap into a 
broad spectrum of cognitive and affective elements, covering learners' beliefs, views, understandings, attitudes, and expectations about physics and learning [3-5,25,26]. Given that a philosophical debate of what counts as epistemology is beyond the scope of the study, we follow the PER convention in our current work to examine, in a broad sense, learners' epistemological views about physics and learning physics.

\section{B. Discipline-based epistemological beliefs}

Just as learning is contextualized, learners' views about knowledge, knowing, and learning can also vary remarkably across different settings or domains $[27,28]$. The same students who demonstrate sophisticated epistemological understandings in one subject matter may show less expertlike views in another domain. Such unevenness in the learners' epistemologies has led researchers to the notion that epistemological beliefs are domain specific $[20,27,28]$. However, in a different camp, scholars who argue learners' thinking is theorylike believe epistemological views may contain certain elements of generality [29-32]. While the domain-generality argument may seem a logical derivation from the theorylike framework, the overwhelming body of empirical results so far has appeared to be more in support of the domain-specificity argument $[19,33,34]$.

As with Elby [22,35], Hammer and Elby [33], Sandoval $[19,24]$, and many others, we consider learners' views about knowledge, knowing, and learning to be best examined in specific domains or disciplines. To this end, and also due to the suitability with a broad range of learners and instructors, we chose the CLASS, a discipline-based survey instrument designed specifically for use in the domain of physics, to gauge the participants' epistemological views about physics and learning physics.

\section{Epistemological development and change}

Despite the accumulating body of literature on learner' epistemologies, there still lacks a shared framework to account for issues such as how students' beliefs develop and change over time $[17,19]$. The stagelike developmental theory of human intelligence initially proposed by Piaget has given rise to a number of similar models of epistemological development, such as Perry's [36,37] intellectual and ethical development scheme, Baxter Magolda's [38,39] epistemological reflection model, King and Kitchner's [40] reflective judgment model, and Kuhn's [41] reasoning model. These models all proposed a somewhat linearly sequenced developmental path from novicelike, less sophisticated to expertlike, more sophisticated epistemological beliefs.

Shifting away from such sequenced structure and drawing on the contextualized nature of epistemologies, Hammer and Elby $[1,33]$ proposed a resource framework to explain how students' views may be affected by specific contexts. This model, as pointed out by Sandoval [24], although useful for describing novice learners' use of epistemological resources, remains unclear on how learners' views develop and what may influence the development.

While there is no consensus on any specific model, researchers do agree that multiple factors, such as classroom teaching, motivation, and expectation, may affect learners' epistemological beliefs [22,24]. Studies in the physics education research community thus far have looked heavily into the impact of classroom teaching on students' views about the nature of physics and learning physics [4250]. An emerging pattern from such studies indicates that conventional, and even many reformed, teaching practices seem incapable of producing positive outcomes, but classes that explicitly and reflectively address learners' epistemologies may result in an improvement on students' views [8].

However, to date little is known about what or how other factors besides classroom instruction may influence learners' views about the nature of physics and learning physics. In fact, to the best of our knowledge there is no empirical study examining such factors at the turning points of learners' entering or exiting higher institutions and embarking on their professional careers. Even a few studies that marginally touched upon this topic using the crosssectional survey design did not delve into the underlying mechanisms behind their quantitative findings $[13,14]$.

To fill this gap in the literature, our study is specifically directed toward identifying and explaining the changes in epistemological views among a group of Chinese preservice and in-service teachers. By so doing, we are not only able to sketch out a rough progression trend from incoming freshmen to in-service teachers, but also able to cast new light on factors other than classroom instruction that can impact individuals' epistemological views.

\section{METHODOLOGY}

\section{A. Participants and contexts}

The subjects of interest in the current study are Chinese undergraduates studying for their baccalaureate degree to become high school physics teachers and 1st-year high school teachers who were about to start their 2nd year of teaching. All of the participants were either enrolled in, at the time of the study, or had already graduated from the same undergraduate program at a comprehensive research university in China that is equivalent to large state research institutions in the U.S. Housed in the physics department, this 4-year undergraduate program was sponsored by the federal government to produce high school physics teachers so as to meet the increasing demands of secondary education in China. It is worth noting that unlike the case in the U.S., physics (along with biology, chemistry, and geology) is a compulsory science course for all high schoolers. In fact, physics begins as a standalone science course at grade 8 and continues into the last year of high school. 


\begin{tabular}{|c|c|c|c|c|c|c|c|}
\hline $\begin{array}{c}\text { Cohort } \\
\text { (No. of participants) }\end{array}$ & $\begin{array}{l}\text { Beginning of } \\
\text { Freshman Year } \\
\text { (Pre-University) }\end{array}$ & $\begin{array}{c}\text { End of } \\
\text { Freshman Year }\end{array}$ & $\begin{array}{c}\text { End of } \\
\text { Sophomore Year }\end{array}$ & $\begin{array}{l}\text { End of } \\
\text { Junior Year }\end{array}$ & $\begin{array}{c}\text { End of } \\
\text { Senior Year }\end{array}$ & $\begin{array}{c}\text { End of } \\
\text { 1st Year of In- } \\
\text { Service Teaching }\end{array}$ & $\begin{array}{c}\text { End of } \\
2^{\text {nd }} \text { Year of In- } \\
\text { Service Teaching }\end{array}$ \\
\hline $\begin{array}{c}\text { Cohort A } \\
(n=36)\end{array}$ & Pre & Post & & & & & \\
\hline $\begin{array}{r}\text { Cohort B } \\
(n=31)\end{array}$ & & Pre & Post & & & & \\
\hline $\begin{array}{r}\text { Cohort C } \\
(n=40)\end{array}$ & & & Pre & Post & & & \\
\hline $\begin{array}{l}\text { Cohort D } \\
(n=36)\end{array}$ & & & & Pre & Post & & \\
\hline $\begin{array}{l}\text { Cohort E } \\
(n=34)\end{array}$ & & & & & Pre & Post & \\
\hline $\begin{array}{l}\text { Cohort F } \\
(n=42)\end{array}$ & & & & & & Pre & Post \\
\hline
\end{tabular}

FIG. 1. A Cross-sequential study of six cohorts of participants, each underwent a full academic year of undergraduate studies or inservice teaching. For example, cohort A took the pretest prior to the freshman year (pre-university) and took the post-test at the end of the freshman year. Cohort B, for another example, took the pretest at the end of their freshman year and took the post-test at the end of sophomore year. Cohort F, for yet another example, took the pretest at the end of the 1st year of teaching and took the post-test at the end of the 2nd year of teaching.

Students admitted into this undergraduate teacher preparation program were waived of all tuition and fees for the entire period of higher education but were contracted to teach in high school for at least 10 years after graduation. Because the students were designated to teach physics, the course work they were required to take during the program closely resembled what was designed for the traditional physics majors. This typically included introductory physics in the freshmen year, intermediate level physics in the sophomore and junior years, and advanced courses and thesis projects in the senior year. Additionally, the students were required to take teacher education courses starting in their late sophomore and early junior years. All classes were taught in a traditional style, with the class size ranging from over 100-seat large lectures for the introductory courses to medium lectures of 50 seats for the intermediate and advanced courses. A more detailed description of the program course work is shown in Appendix A, Table I.

\section{B. Instrument}

In the study, we used the validated Chinese translation of CLASS [9] to gauge the participants' epistemological views. The detailed translation and its validation processes have been reported in our previous work (Ref. [9]).

Simply put, CLASS is a 42-item Likert-scale questionnaire, designed specifically to measure learners' views about the nature of physics and the nature of learning physics [10]. Items on the survey can be categorized into 8 subscales, each of which probe, respectively, learners' views on personal interest, real-world connection, problem solving general, problem solving confidence, problem solving sophistication, sense making and effort, conceptual understanding, and applied conceptual understanding. As mentioned before, we chose this survey mainly because of its discipline-specific nature and its suitability with a broad population. In addition, CLASS was designed such that it was not tied to any specific course and could be used with students who never took physics before [10].

\section{Cross-sequential survey design}

We used CLASS as both a pretest and a post-test to track, over a full academic year, six cohorts of participants: incoming freshmen (cohort A), end-of-year freshmen (cohort B), end-of-year sophomores (cohort C), end-of-year juniors (cohort D), end-of-year seniors (cohort E), and 1st-year inservice teachers who had just completed one year of teaching and were about to enter their 2nd year (cohort F). (See Fig. 1 for the number of participants in each cohort). Except for the incoming freshmen who took the pretest during their preuniversity orientation session, all the other participants took the pretest near the beginning of the summer preceding the academic year of 2013 (year 1). After one academic year, all the participants took the CLASS as a post-test at the beginning of the summer of 2014 (year 2). At that time, all the participants had progressed along the continuum from a less advanced level to the next advanced level (see Fig. 1). For instance, the then-incoming freshmen now became end-ofyear freshmen after an academic year, and the then end-ofyear seniors became 1st-year in-service teachers who were about to start their 2nd year of teaching. As such, at each of the five major career points (end of freshman year, end of sophomore year, end of junior year, end of senior year, and end of first-year in-service teaching), there are 2 data sets representing, respectively, the post-test result of a previous cohort and the pretest result of the immediately next cohort (see Fig. 1). For example, at the end of the freshman year, we collected 2 sets of data; one was the post-test result of cohort $\mathrm{A}$, and the other was the pretest result of cohort B. If these two are comparable, it is then legitimate to approximate them into one result to represent the epistemological level for those at this point of their career. Given that all the participants were under the same educational settings, it is sensible to assume 


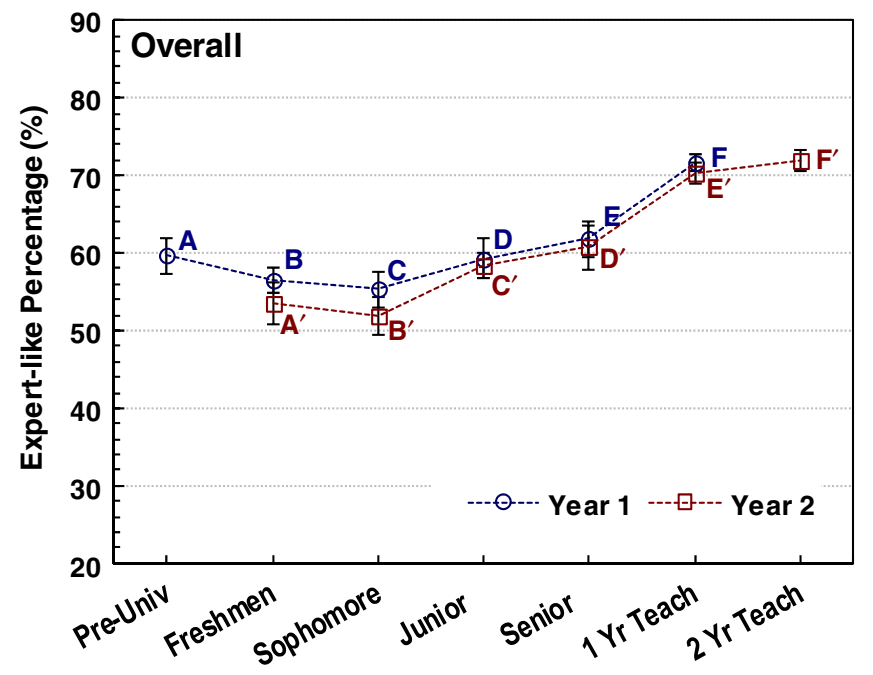

(a)

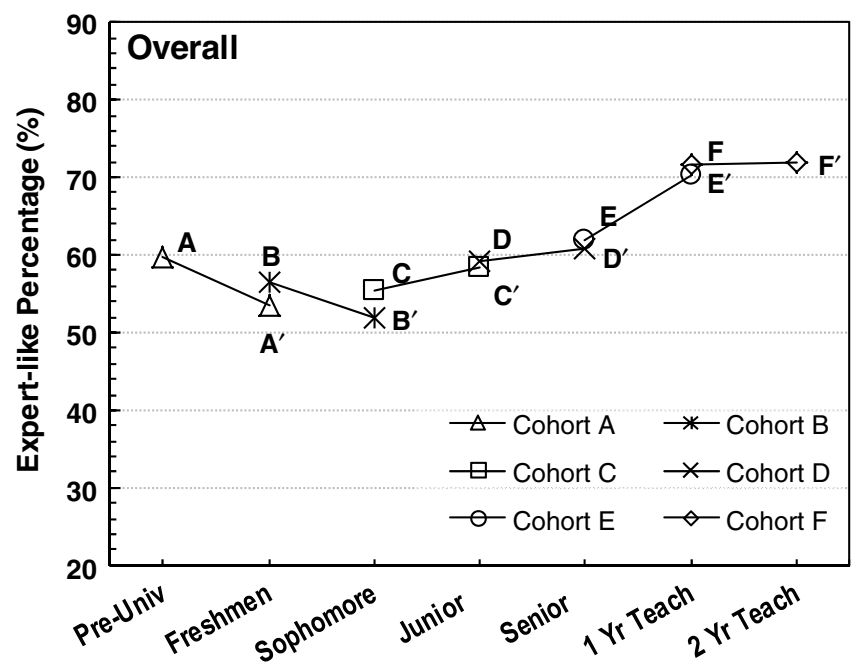

(b)

FIG. 2. Pre and post overall CLASS scores for the six cohorts of participants (cohorts A, B, C, D, E, and F). Marks denoted by alphabetical letters without prime signs are pretest results for each cohort; marks denoted by letters with prime signs are post-test results. Error bars represent standard errors. (a) Two cross-sectional trend lines obtained in two consecutive years. (b) Six longitudinal lines for the six cohorts.

that cohorts with similar epistemological outset at a certain career point would likely exhibit, on average, similar growth within an academic year. Therefore, by comparing and approximating the results at all the five major career points, we can potentially link the multiple longitudinal data sets into an extended sequence, spanning from the beginning of freshmen year to the end of the 2nd-year of in-service teaching.

This approach, namely, the cross-sequential method, provides a means to carry out a series of shorter-term longitudinal studies across multiple cross-sectional cohorts along the continuum of a temporal scale (or, in our case, the number of years in academic studies or teaching careers). In essence, this is a combination of the longitudinal and cross-sectional designs to reduce the otherwise lengthy process of the former and remedy some possible idiosyncrasies of the latter.

All the pre- and post-tests of CLASS were administered as a 15-min, in-class paper-and-pencil survey with no incentives offered. Pre- and postmatched data were then collected for analysis. Note that, by contract, all the inservice teachers within two years of graduation were required to return to their alma mater at the beginning of each summer for a month-long professional development. This allowed us to gain access to all the in-service teachers in two years after their graduation. To ensure the quality of responses, we asked all the participants to take CLASS honestly and seriously.

\section{Qualitative interviews}

Immediately after the post-test we recruited six volunteers from each cohort for one-on-one follow-up interviews. The interviews were semistructured, in which the participants were first asked to verbally respond to all the CLASS items with any elaborations they wished to add. Then they were invited to give free responses to the following three questions: (1) In terms of your own views about physics and learning physics, what do you think has changed since the last academic year? (2) Let's focus on the changes you mentioned. Can you tell me why you had these changes? (3) Is there anything you would like to add? These free-response questions were purposely designed to give the participants an opportunity to freely tell their stories while at the same time prompting them to think reflectively on the nature of physics and learning.

All the interviews lasted approximately $45 \mathrm{~min}$, were videotaped, and later transcribed. The transcriptions were examined independently by the authors to identify any emerging themes regarding the changes (and reasons thereof) in the interviewees' epistemological views. These initial themes were compared between the two authors and were referred back to the original tapes for rechecking. Using these themes as a coding scheme, two additional science education researchers analyzed the interview transcriptions. This resulted in merging, adding, or deleting components of the scheme, and finally it converged to a set of themes that were fully agreed upon by all the four researchers. These themes, as reported in Section IV, captured major shifts in the interviewees' epistemological views.

\section{RESULTS AND FINDINGS}

\section{A. Survey results}

\section{Overall performance on CLASS}

Since we used CLASS with each of the six cohorts twice, we obtained 12 data sets. Figure 2(a) shows the 
performance of the participants on the overall CLASS. As seen, there are 12 marks in the figure, indicating the average scores (or expertlike percentages) for the cohorts. The circular marks, labeled as A, B, C, D, E, and F, represent the six pretest scores for the six cohorts collected in 2013 (year 1). The square marks, labeled as $\mathrm{A}^{\prime}, \mathrm{B}^{\prime}, \mathrm{C}^{\prime}$, $\mathrm{D}^{\prime}, \mathrm{E}^{\prime}$, and $\mathrm{F}^{\prime}$, represent the six post-test scores collected in 2014 (year 2). Labels of the same letter denote the same cohort, and the prime sign indicates the post-test.

With these notations, we see (by tentatively disregarding the within-cohort changes) two cross-sectional trend lines in Fig. 2(a), one connecting all the circular marks (pretest in year 1) and the other connecting all the squares (post-test in year 2). The two trend lines share five major time points (end of freshman year, end of sophomore year, end of junior year, end of senior year, and end of 1st-year of in-service teaching). As shown, these two lines are remarkably close. We conducted an independent-sample comparison between the two marks at each of the five time points and found no statistical significance for any of them [all $\chi^{2}(1) \leq 1.011$, all $\left.p^{\prime} \mathrm{s} \geq 0.315\right]$. This suggests that the cross-sectional trend obtained in year 1 does not deviate significantly from the trend measured in year 2. Note that we used the nonparametric Wilcoxon-Mann-Whitney test for the independent-sample comparisons. This is because several of the data sets failed to meet the normality requirement [51]. Unless otherwise indicated, in the remainder of the paper we only report nonparametric statistics.

To uncover any differences between the cohorts, we conducted a Kruskal-Wallis test (an ANOVA equivalent for nonparametric) for each of the two trend lines. In both cases (years 1 and 2), there was a significant difference across the six cohorts [year 1: $\chi^{2}(5)=43.44, p<0.0001$; year 2: $\left.\chi^{2}(5)=61.93, p<0.0001\right]$. Additional multiple comparisons showed that the significance was mainly from the difference between those at the end of senior year and those at the end of the 1st year of in-service teaching [year 1: $\chi^{2}(1)=11.51, p=0.0007$, effect size (E.S.) $=0.39$; year 2: $\chi^{2}(1)=4.89, p=0.027$, E.S. $\left.=0.30\right]$.

This result was further verified by examining the six longitudinal segments as highlighted in Fig. 2(b). With exactly the same marks as before, Fig. 2(b) connects the pretest with the post-test of the same cohort to reveal the actual longitudinal shifts. A Wilcoxon signed rank test, a nonparametric one-sample comparison, was conducted for each of the six cohorts. It was found that only the positive shift for cohort E (end-of-year seniors) was shown to be significant $(S=162.5, p=0.0023$, E.S. $=0.35)$, the same result as what was found from the cross-sectional comparisons.

Perhaps the most important feature of Fig. 2(b) is that it reveals an overall progression trend better than Fig. 2(a). Recall that the two marks at each of the five career points (from the end of freshman year to the end of the 1st-year of in-service teaching) were statistically comparable.
Therefore, it is legitimate to link the six longitudinal segments into an extended sequence and approximate it as a progression trend. This gives us a closer-to-actual progression line than before.

Piecing together all of the above results, it is now clear that students' views about physics and learning physics, as measured by CLASS, changed little during their undergraduate studies. However, those in-service teachers who had just left higher education and were in their 1st-year of high school teaching demonstrated a significant improvement in their epistemological views measured by the CLASS. More interestingly, such an improvement did not appear to continue among those who were in the second year of their teaching career.

\section{Performance on individual categories}

Besides the overall CLASS scores, we also looked into the participants' performances on the 8 categories covered by the survey. Following the same notations as in Fig. 2(b), we show in Fig. 3 the longitudinal shifts on these categories for the six cohorts. For brevity, we skip the cross-sectional lines here. As with before, in each case the six longitudinal lines can be thought of as six segments along an extended, continuous progression line. This is because at any of the five major time points (from the end of freshman year to the end of the 1st-year of in-service teaching), the two marks were statistically comparable [all $\chi^{2}(1) \leq 1.739$, for all $p \geq 0.187]$. Even in the most seemingly divergent cases of the "real world connection," "sense making," and "conceptual understanding" categories, the differences between the two marks at these time points were not significant [see, for example, marks A' and B in Fig. 3(b), marks A' and B in Fig. 3(f), and marks B' and C in Fig. 3(g)].

Similarly to the above analysis, we performed a Wilcoxon signed rank test for each of the six cohorts to see if there was any significant change between the pre- and post-tests. It was found that both cohort A incoming freshmen and cohort E end-of-year seniors exhibited a significant shift on several categories, and for the most part these shifts were of a medium-large effect size (E.S. $\geq 0.30$ ) [52]. While a couple of other cohorts also showed a statistically meaningful change on one or two categories, all the magnitudes were of a small size (E.S. $<0.30)$. For brevity and for better serving the goal of the study, we focus specifically on the major changes demonstrated by cohort A and cohort E. Interested readers can find a complete list of statistical results accompanied by effect sizes in Appendix B, Table II.

Cohort A: Incoming freshmen Although there was no significant shift on the overall CLASS performance, the incoming freshmen revealed a number of major decreases on several individual categories. These were "problem solving general" $(S=148, p=0.002, \quad$ E.S. $=0.34)$, "problem solving confidence" $(S=125.5, p=0.001$, 


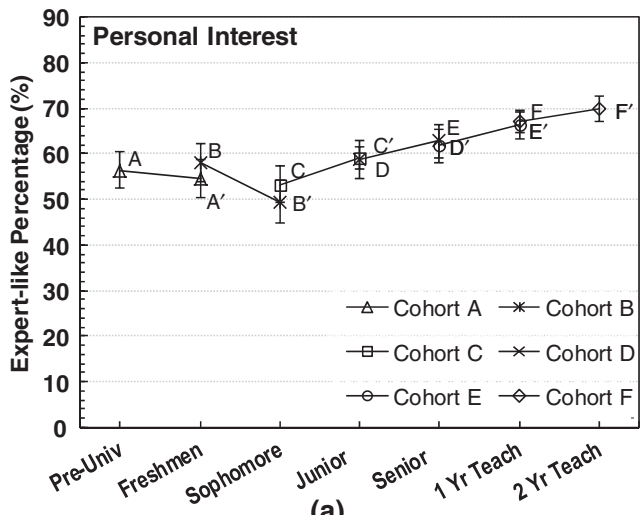

(a)

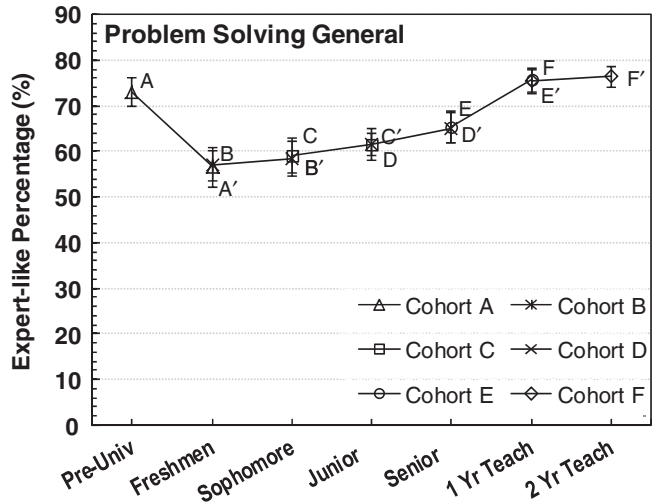

(c)

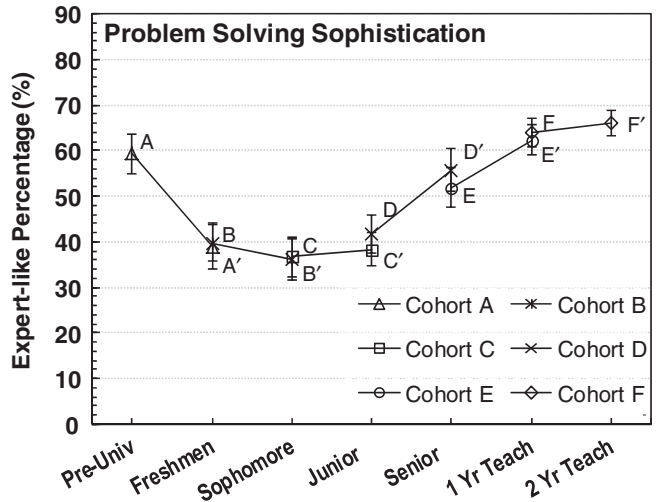

(e)

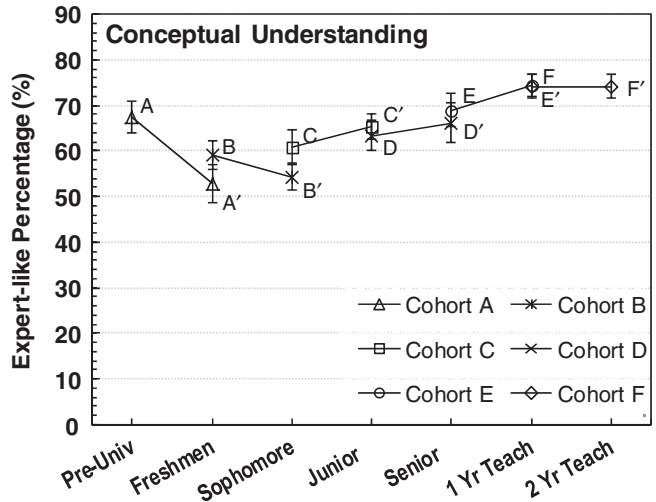

(g)

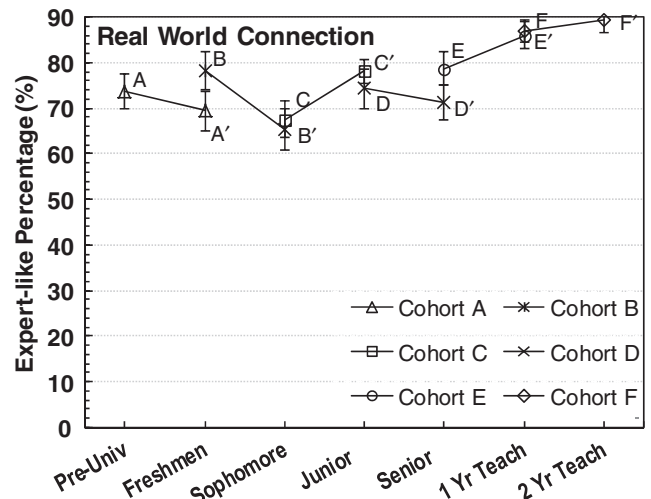

(b)

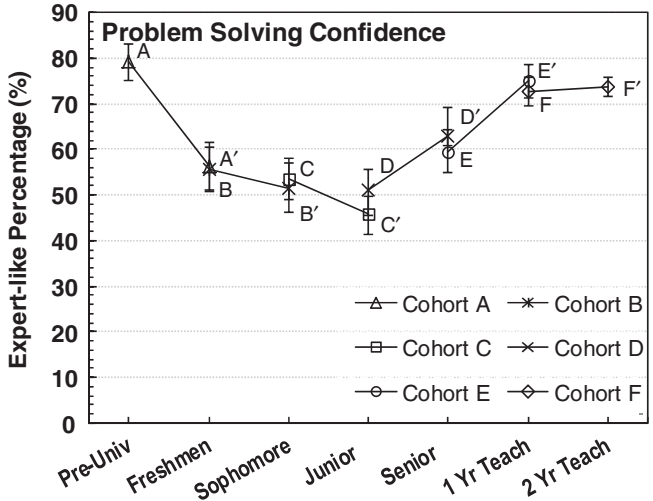

(d)

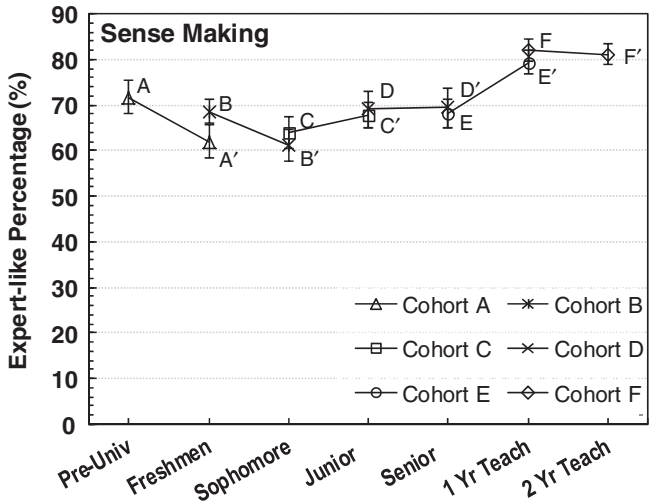

(f)

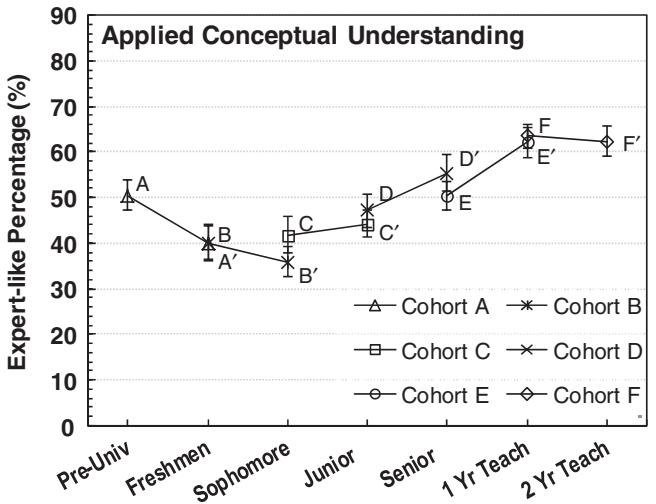

(h)

FIG. 3. Sequential trend lines denoting the longitudinal shifts on the 8 categories of CLASS for participants in cohorts A, B, C, D, E, and F. Error bars represent standard errors. (a) Personal interest, (b) real-world connection, (c) problem solving general, (d) problem solving confidence, (e) problem solving sophistication, (f) sense making, (g) conceptual understanding, and (h) applied conceptual understanding. 
E.S. $=0.36)$, and "problem solving sophistication" $(S=117.5, p=0.005$, E.S. $=0.32)$, where the decreases were both significant and of a medium-large size (also see Appendix B). In other words, the data showed that those who had left high school to attend college became more novicelike in their views about physics problem solving after one year of higher education. They became less interested, less confident, and less sophisticated in this matter.

Cohort E: End-of-year seniors As a sharp contrast to the incoming freshmen, cohort $\mathrm{E}$ demonstrated a significant increase on several categories (see Appendix B). Two of the categories were "problem solving general" $(S=115.5$, $p=0.013$, E.S. $=0.30)$ and "problem solving confidence" $(S=85.5, p=0.009$, E.S. $=0.31)$, and another one was "sense making and effort" $(S=114, p=0.002$, E.S. $=0.35)$. All the increases appeared to be a medium size. In light of these findings, it seemed that the end-ofyear seniors began to demonstrate more expertlike views about problem solving and sense making during their first year of in-service teaching. They became more confident in handling physics problems and increasingly believed that the proper way to approach physics was investing efforts in sense making.

Interestingly enough, after having completed a year of teaching, those in cohort $\mathrm{F}$ who continued into their second year of teaching did not show significant increase or decrease on any of the categories, a finding fairly similar to what was observed among the undergraduates in cohort $\mathrm{B}$, cohort $\mathrm{C}$, and cohort D.

\section{B. Interviews}

Since all the nontrivial epistemological changes as measured by CLASS occurred among cohort A and cohort E, we looked specifically into these two cohorts to explore possible factors that may account for the changes.

\section{Cohort A: Incoming freshmen}

As reported above, although the participants' overall performance on the CLASS did not show a statistical decrease after a year of undergraduate studies, their views about problem solving as reflected on the three pertinent categories became more novicelike. From the student interviews, three major themes emerged, revealing some underlying factors that could link to the observed changes. These themes related respectively to the highly competitive environment in college, increased difficulty in course content, and drastically different instructional practices in college classes from those in high school.

Half of the interviewees either explicitly mentioned or alluded to the fact that the competitive environment in college somehow took its toll on them, making them lose confidence or interest in physics. For instance, one student stated
"When I was in high school, I was always ranked high in physics. Back then I focused on how to solve problems, especially the hard ones, and that made me feel accomplished. Now I am in college. Many of my fellow students are doing better than I am. It's like learning physics is not so much about tackling problems but more about competing against others. When running into hard problems, I often wonder if it's because the problems are hard or maybe because I'm not smart enough."

Similarly, another student attributed success in problem solving to intelligence and expressed frustration when he could not outperform his peers.

"So, you ask me how learning physics in college is different than in high school. I think the biggest difference is that you suddenly find yourself surrounded by so many people who are the cream of the crop. At the beginning I wanted to work hard, but later I realized that all the hard work was for nothing. Challenging problems are only created for the best and brightest people to solve. People like me, no matter how much time I spend, I still can't get it. So, I won't do that. I am frustrated, because most of the time I feel like I can only get part of the story straight..."

A second major factor raised by two-thirds of the interviewees that influenced their views about physics and learning physics was the increased difficulty level of the course content. One student articulated this point.

"I really liked physics when I was in high school. It was my favorite subject. I did very well on exams, learned a lot, and felt really interested. I basically had a very good handle on the content. Problems that others did not know how to do, I was able to solve... But after I attended college, I came to realize that this field is so extensive and profoundly deep. There is no way you can learn all of it. It is no longer like the same physics I knew in high school. I could spend days studying and still felt like I was not getting to the core of it. That kind of breadth and depth, that kind of infinite broadness, somehow hurts my confidence. Now I both love and hate physics, maybe hate more than love. I think I have shifted from a person who aspired to learn physics to someone who is tormented by it and shuns away from it."

Another student took the vector expression of work as an example to illustrate how he viewed problem solving in college.

My feeling is that the formulas and concepts taught in the 1st year intro physics is more or less the same as in high school, except that some formulas become vector equations. So Ifeel nothing too surprising. But somehow I find none of the formulas useful for solving problems. 
Like the work formula $W=\vec{F} \cdot \vec{S}$, I don't know how to solve a problem if the direction of a force is constantly changing and the displacement of an object no longer follows a straight line."

Perhaps the most recurrent issue that impacted all but one students' views about physics was the different instructional styles in college classes they were experiencing. Below is what a student stated.

"College teaching is extremely fast-paced. What seems to be a whole semester of materials in high school is crammed into one month in college. In high school our teacher asked us to do a lot of practice problems after each topic. Then we would discuss different problem types and problem solving strategies. But college instructors only give us a few homework problems. That's it. Then we move on to the next new topic. All I know is that every time I am in a physics class, there are new topics, talking about new topics constantly. I end up having to take in new stuff even before I can be sure I understand what I've learned before."

The same sentiment was voiced by others as well, for example,

"College teaching is just like $1 D$ uniform motion at a
constant speed: one chapter a week, regardless of how
hard the topics are; very few quizzes and no review
lessons; just moving on and on. In high school, we had
monthly exams, before which we would do a lot of
review, and after which we'd spend a class going over
the exam problems again. You know, it might be ok to
keep introducing new topics nonstop if it were a social
sciences class. But how can we possibly do that in
physics? Idon't even remember what I've learned in the
previous class or can't be sure that I've understood it
all, and now I'm already moving on the next topic..."

\section{Cohort E: End-of-year seniors}

Contrary to the incoming freshmen, end-of-year seniors demonstrated a significant increase in their views about problem solving and sense making during their first year of teaching. On this matter, our interviews revealed two emerging themes, each mentioned by at least two-thirds of the interviewees and relating, respectively, to the low difficulty level in high school physics and role change from student to teacher.

Relative to college physics, the low difficulty in high school physics appeared to have liberated the 1st-year teachers and freed up their attention for more sense making. One teacher interviewee pointed out the following:

"I've always liked physics since I started it. Maybe it's my fate. All my physics teachers somehow made me love it more. Eventually I chose this major and became a teacher myself. From learning at university to teaching in high school, I feel what has changed is the technicality level of the subject matter that I am dealing with. It hasn't increased but instead goes down, and at the same time my enthusiasm for physics education has gone up. That's because high school physics is very straightforward. So I no longer need to struggle with the content or cope with those cutting-edge topics. Instead I can focus on how to do a better job in making meaning and instruction design."

This response was echoed by another interviewee who put it this way:

"Back in high school, physics was my forte. I could clearly understand what was taught in class and had no trouble doing most problems. I liked it and did it well... But after I went to college, I was shocked to find that physics was so broad and extensive... I felt physics was very hard in college. I later began teaching, picking up high school physics again, and suddenly things became crystal clear to me. Maybe it was because university physics made me see the deep connections between concepts, forcing me to see a big picture. That may have helped me handle high school physics more easily. In the past year, I placed great emphasis on sense making. Before solving each problem, I always start with a discussion of the deep structure and focus on the relevant concepts before calculation. But students don't seem to care for making of the concepts. They care more about formulas, using formulas to do calculation."

Besides content difficulty, the role change from student to teacher was also an important factor. It brought about a sense of responsibility, a deep appreciation for meaning making, and an epiphany about the nature of learning. For instance, below is an excerpt from an interviewee who encountered this change.

"As a student in college, I was just doing pretty much what I felt like, 'cause that wouldn't affect anyone else but me. So, if I didn't feel like it, I would just try to find an easy way out. I didn't care too much about where the formulas came from. I would copy others' homework if I had no clue about how to do it. Cramming for exams got me through the classes pretty well. Now that I've become a teacher, I have to be more responsible, preparing for daily classes, teaching, and helping students... I came up with anything and everything possible, talking about everyday physics as real examples, discussing concepts from multiple angles, presenting various types of problems, offering different solutions to the same problem, review, practice..."

Another interviewee mentioned that being a teacher made her increasingly cognizant of the importance 
of making efforts to understand concepts. Specifically, she said,

"Generally speaking, when I was a student, I focused a lot on fragmented knowledge pieces and didn't really attend to their interconnections. Since I was good at rote memorization, I didn't feel like I needed to use the concept map to comb through my knowledge. After I became a teacher, I began to understand its importance. Every student is a unique individual with different cognitive capabilities. Fragmented learning doesn't help understand physics at all. A year of teaching made me increasingly aware of the tight connections among all sorts of concepts. Making efforts to connect the dots is very important, and so is constant review that helps to lay a solid foundation. Otherwise, any subsequent teaching and learning won't go well."

Yet another interviewee directly spoke of her change in views about learning.

"After I went to college, I suddenly found physics very hard; sometimes I'd end up with nothing even after racking my brain. I remember one of my professors said that the responsibility of learning rests with us. Back then I thought it was just an excuse to shift the blame for the professor's poor teaching. Now as a high school teacher, I genuinely believe the majority of us are responsible; I myself is such a case... I think hard every day about how to teach better... Every topic and problem I discuss in class is carefully thought out and presented from different angles. But even so, some of my students still can't get it. I think it is really important to increase student interest in learning physics and develop their independent thinking skills and habits of mind. After all, I've experienced both roles of a student and a teacher."

In short, our interviews showed that the highly competitive environment in college, increased difficulty of course content, and drastically different instructional practices in college classes were the main factors that had negatively affected the incoming freshmen's views about physics and learning physics. Conversely, the relatively easy content in high school physics and role change from student to teacher favorably influenced the end-of-year seniors' epistemological views.

\section{DISCUSSION AND IMPLICATIONS}

Bringing together the above results allows us to have a glimpse of what a progression trend may look like for our participants in their views about physics and learning physics. From the beginning of the freshman year to the end of 2nd year of in-service teaching, the epistemological trend as measured by CLASS did not appear to be a monotonic increase. Instead, there was a slight decrease among the incoming freshmen during their first year of undergraduate studies, and such a decrease was primarily rooted in views about problem solving (Fig. 3). Moving on to the next stage, our participants who completed their freshmen year and were ready to begin their sophomore year seemed to have reached a stasis, where little change in their epistemological views was detected despite their continuing higher education. In fact, this situation persisted until the end of the senior year. Also worth noting is that such a stasis was found both in the overall CLASS performance and, for the most part, in the individual categories [see Figs. 2(b) and 3].

Interestingly, after the participants left college and began their teaching career, their views about physics and learning physics showed a noticeable rebound, particularly on the categories of problem solving and sense making [see Figs. 2(b) and 3]. That said, the rebound did not show signs of continuing into the second year of teaching. Instead, those who finished their first year of teaching seemed to have reached a new plateau of some sort, where their epistemological views exhibited nearly no change as they went through their 2nd year of teaching.

The "decrease, leveling out, increase, and leveling out again" pattern by and large sketched out an epistemological progression trend that extends from the beginning of the freshman year to the end of the 2nd year of teaching (research question 1). Along this career line, two significant changes that took place, respectively, during the first year of higher education and during the first year of teaching were noticeable (research question 2). Our follow-up interviews with the participants revealed several major themes that could account for the identified changes. These themes related to both instructional and noninstructional factors, such as competitive learning environment, increased content difficulty, and unfamiliar university pedagogies faced by the incoming freshmen, and relatively easier content and identity change experienced by the exiting seniors during their 1st year of teaching (research question 3). One point worth mentioning here is that these identified themes revealed several underlying factors linking to our observed changes in the participants' epistemologies. But it perhaps is premature to consider them as the only factors or as the definitive causes.

That said, it is clear from our interviews that the participants' epistemological views about physics and learning physics were closely intertwined with their selfimage, motivation, and even moral sense; factors that are beyond classroom instructions. For our incoming freshmen in particular, they successfully rose above the rigid competition of the National University Entrance Examination and came to higher education with a strong sense of selfpride, but only found themselves overwhelmed with even 
more competitive rivals, so to speak, in their physics classes. Holding off our critiques on their pride, it is perhaps important for us to first recognize and acknowledge the potential influences of the competition-driven attitudes on learners' approaches to learning. More importantly, it may be beneficial for us to start seeking measures that can mitigate an overly heightened level of competition in Chinese universities or for that matter in any other institutions. For example, we can consider using criterionreferenced assessments more than norm-referenced assessments to shift the students' attention from winning over their peers to winning over the course material. Perhaps, this not only can offer some protection of student selfimage, but may also help shape mastery-oriented motivation toward learning.

Similarly to the self-image shift experienced by the incoming freshmen, our end-of-year seniors went through a drastic role change in their 1st year of teaching that quite profoundly affected their views toward physics. This change from student to teacher equipped our graduated seniors with a stronger sense of responsibility and sparked an epiphany about the real meaning of learning. It is interesting to witness our interviewees contrast their perspectives as both a student and a teacher. Some even went further by comparing their own views with the views of their students. This powerful impact that the role change brought about made us wonder how, if at all possible, a comparable level of epistemological epiphany could be created in the classrooms of our higher education. Research effort along this line has been burgeoning, but the findings are still largely disappointing despite a few studies of some reformed curricula suggesting otherwise. One implication that can be extracted from our current study is that providing students with an opportunity to experience a role change from student to instructor may be beneficial. Of course, this needs to be more than just assigning students to teach a session but instead to include a component of holding them accountable for the learning of their audience as well as their own; the same way the teachers were responsible for their students' learning. By doing so, a more authentic experience of role change may be simulated in classroom to facilitate learners' epistemological changes.

As with the previous literature, our work also revealed the influence of classroom instruction on learners' views about physics and learning physics. However, rather than focusing on pedagogical analysis of traditional or reformed physics instructions in relation to learners' epistemologies, our study provided quite elaborated accounts, from the participants' perspectives, of the sharp contrast between university teaching and high school teaching as an important contributing factor to the learners' view shift. Additionally, the increased difficulty level inherent in the college physics was found to negatively influence the incoming freshmen's epistemological views. Consistently, we observed the opposite case of graduated seniors returning to high school physics as teachers, in which a decrease in content difficulty appeared to have freed up the participants' minds and hence allowed them to focus more on sense making and conceptual reasoning. To a large extent, these findings reflected a concerning fact that our participants experienced a great discomfort with college teaching and learning. This discomfort was mainly from our students' overreliance on their high school teachers to feed them test-taking or problem solving tactics. Since university instructors were not under the same pressure to prepare students for national examinations as did high school teachers, education at the tertiary level rarely invested in rote practicing. As a result, the incoming freshmen who had become deeply accustomed to high school teaching could no longer easily adapt to the college norms.

Certainly, this is a much broader and more systematic issue in Chinese education, which inevitably demands concerted efforts from researchers, instructors, administrators and policy makers to bring up changes. That said, it is important that we first identify, acknowledge, and understand the roots of the issues. After all, any successful solution to a problem begins with knowing what the problem is. To this end, by sketching out a trend and identifying some influencing factors on the learners' epistemological views, we hope our study has taken some initial steps toward the ultimate goal of best preparing our next generation workforce with more constructive views about science and learning science.

\section{ACKNOWLEDGMENTS}

The authors wish to thank Jing Zhang for her assistance in the study and the two anonymous reviewers for their insightful comments that have helped us to strengthen the manuscript. The work is partially supported by 2015 Comprehensive Discipline Construction Fund of Faculty of Education, Beijing Normal University (No. 2015GJXM002) and National Science Foundation No. DRL-1252399. 


\section{APPENDIX A: UNDERGRADUATE COURSEWORK FOR PRESERVICE TEACHERS}

TABLE I. Undergraduate coursework required of the students in the physics teacher education program.

\begin{tabular}{|c|c|c|c|c|c|c|c|c|c|c|c|c|}
\hline \multirow[b]{3}{*}{ Course type } & \multirow[b]{3}{*}{ Course title } & \multirow[b]{3}{*}{ Credit } & \multicolumn{8}{|c|}{ Semester and weekly hours } & & \\
\hline & & & \multicolumn{2}{|c|}{ Year 1} & \multicolumn{2}{|c|}{ Year 2} & \multicolumn{2}{|c|}{ Year 3} & \multicolumn{2}{|c|}{ Year 4} & \multicolumn{2}{|c|}{ Course evaluation } \\
\hline & & & I & II & III & IV & $\mathrm{V}$ & VI & VII & VIII & $\begin{array}{c}\text { Pass } \\
\text { and Fail }\end{array}$ & $\begin{array}{l}\text { Exam } \\
\text { (Grades) }\end{array}$ \\
\hline \multirow{7}{*}{$\begin{array}{l}\text { General education } \\
\text { courses }\end{array}$} & Ideology and Political Sciences & 14 & 2 & 2 & 2 & 2 & 2 & & & & & $\checkmark$ \\
\hline & University English & 10 & 5 & 5 & & & & & & & & $\checkmark$ \\
\hline & Information Technology & 5 & 2 & $2+2$ & & & & & & & & $\checkmark$ \\
\hline & $\begin{array}{l}\text { Fitness, Wellness, and Physical } \\
\text { Education }\end{array}$ & 4 & 1 & 1 & $\checkmark$ & $\checkmark$ & $\checkmark$ & $\checkmark$ & & & $\checkmark$ & \\
\hline & Aesthetics Education & 2 & 2 & & & & & & & $\checkmark$ & & \\
\hline & Military Theory and Training & 2 & & 2 & & & & & & & & $\checkmark$ \\
\hline & $\begin{array}{l}\text { Interpersonal and Public } \\
\text { Electives }\end{array}$ & 7 & & $\checkmark$ & $\checkmark$ & $\checkmark$ & $\checkmark$ & $\checkmark$ & & & & $\checkmark$ \\
\hline \multirow{15}{*}{$\begin{array}{l}\text { Compulsory } \\
\text { courses }\end{array}$} & University Mathematics & 18 & 6 & 6 & 6 & & & & & & & \\
\hline & Mechanics & 4 & 4 & & & & & & & & & $\checkmark$ \\
\hline & Electromagnetism & 4 & & 4 & & & & & & & & $\checkmark$ \\
\hline & Thermal physics & 2 & & & 2 & & & & & & & $\checkmark$ \\
\hline & Optics & 3 & & & 3 & & & & & & & $\checkmark$ \\
\hline & Quantum Physics & 3 & & & & 3 & & & & & & $\checkmark$ \\
\hline & Introductory Physics Lab & 4 & & 4 & 4 & & & & & & & $\checkmark$ \\
\hline & $\begin{array}{l}\text { Mathematical Methods for } \\
\text { Physics I }\end{array}$ & 4 & & & 4 & & & & & & & $\checkmark$ \\
\hline & Modern Physics Lab I & 2 & & & & & 4 & & & & & $\checkmark$ \\
\hline & $\begin{array}{l}\text { Fundamentals of } \\
\text { Computational } \\
\text { Physics }\end{array}$ & 3 & & & & $2+2$ & & & & & & $\checkmark$ \\
\hline & Classical Mechanics & 3 & & & & 3 & & & & & & $\checkmark$ \\
\hline & Electrodynamics & 3 & & & & & 3 & & & & & $\checkmark$ \\
\hline & Quantum Mechanics & 3 & & & & & 3 & & & & & $\checkmark$ \\
\hline & $\begin{array}{l}\text { Thermodynamics \& Statistical } \\
\text { Physics }\end{array}$ & 3 & & & & & & 3 & & & & $\checkmark$ \\
\hline & Solid State Physics & 2 & & & & & & 2 & & & & $\checkmark$ \\
\hline \multirow{15}{*}{$\begin{array}{l}\text { Elective courses } \\
\text { (minimum } \\
19 \text { credits) }\end{array}$} & $\begin{array}{l}\text { Mathematical Methods for } \\
\text { Physics II }\end{array}$ & 2 & & & & 2 & & & & & & $\checkmark$ \\
\hline & Modern Physics Lab II & 2 & & & & & 4 & & & $\checkmark$ & & \\
\hline & Electronic Circuits & 3.5 & & & & $3+1$ & & & & & & $\checkmark$ \\
\hline & Superconductivity & 3 & & & & & & & & 3 & & $\checkmark$ \\
\hline & Semiconductor Physics & 3 & & & & & & & 3 & & & $\checkmark$ \\
\hline & Condensed Matter Physics & 3 & & & & & & & & 3 & & $\checkmark$ \\
\hline & $\begin{array}{l}\text { Solid State Physics } \\
\text { Special Topics }\end{array}$ & 3 & & & & & & & 3 & & & $\checkmark$ \\
\hline & Analysis of Material Properties & 3 & & & & & & & & 3 & & $\checkmark$ \\
\hline & General Relativity & 4 & & & & & 4 & & & & $\checkmark$ & \\
\hline & $\begin{array}{l}\text { Introductory Physics } \\
\text { Special Topics }\end{array}$ & 3 & & & & & & & & 3 & & $\checkmark$ \\
\hline & Principles of Laser & 2 & & & & & & 2 & & & $\checkmark$ & \\
\hline & $\begin{array}{l}\text { Probability \& Mathematical } \\
\text { Physics }\end{array}$ & 3 & & & & & 3 & & & & & \\
\hline & Frontiers of Modern Physics & 2 & 2 & & $\checkmark$ & & $\checkmark$ & & & & & $\checkmark$ \\
\hline & Introduction to Biophysics & 3 & & & & & & 3 & & & & $\checkmark$ \\
\hline & $\begin{array}{l}\text { Multimedia Programming } \\
\text { Design }\end{array}$ & 4.5 & & & & & $3+3$ & & & & & $\checkmark$ \\
\hline
\end{tabular}




\begin{tabular}{|c|c|c|c|c|c|c|c|c|c|c|c|c|}
\hline \multirow[b]{3}{*}{ Course type } & \multirow[b]{3}{*}{ Course title } & \multirow[b]{3}{*}{ Credit } & \multicolumn{8}{|c|}{ Semester and weekly hours } & & \\
\hline & & & \multicolumn{2}{|c|}{ Year 1} & \multicolumn{2}{|c|}{ Year 2} & \multicolumn{2}{|c|}{ Year 3} & \multicolumn{2}{|c|}{ Year 4} & \multicolumn{2}{|c|}{ Course evaluation } \\
\hline & & & $\mathrm{I}$ & II & III & IV & $\mathrm{V}$ & VI & VII & VIII & $\begin{array}{l}\text { Pass } \\
\text { and Fail }\end{array}$ & $\begin{array}{c}\text { Exam } \\
\text { (Grades) }\end{array}$ \\
\hline \multirow[t]{10}{*}{$\begin{array}{l}\text { Elective courses } \\
\text { (Con't) }\end{array}$} & $\begin{array}{l}\text { Principles of Micro-computer } \\
\text { and Interface Technology }\end{array}$ & 4.5 & & & & & & $3+3$ & & & & $\checkmark$ \\
\hline & $\begin{array}{l}\text { Differential Geometry and } \\
\text { General Relativity }\end{array}$ & 4 & & & & & 4 & & & & & $\checkmark$ \\
\hline & History of Physics & 2 & & $\checkmark$ & & $\checkmark$ & & $\checkmark$ & & & & $\checkmark$ \\
\hline & Physics Labs Special Topics & 2 & & & & 4 & & & & & $\checkmark$ & \\
\hline & Electronics and Labs & 3 & & & & & $2+2$ & & & & & $\checkmark$ \\
\hline & Astronomy & 3 & & & & & 3 & & & & & \\
\hline & $\begin{array}{l}\text { Basics of Engineering } \\
\text { Graphics and CAD }\end{array}$ & 3 & & & & $2+2$ & & & & & & $\checkmark$ \\
\hline & Fortran & 3 & & & & & & $2+2$ & & & & $\checkmark$ \\
\hline & Principles of Optics & 4 & & & & & 4 & & & & & $\checkmark$ \\
\hline & Intercollege Electives & 4 & & & & & $\checkmark$ & $\checkmark$ & & $\checkmark$ & & \\
\hline \multirow{5}{*}{$\begin{array}{l}\text { Teacher education } \\
\text { compulsory } \\
\text { courses }\end{array}$} & Educational Psychology & 2 & & & & 2 & & & & & & \\
\hline & Education Theories & 2 & & & & & 2 & & & & & \\
\hline & Educational Technology & 3 & & & & & 2 & -2 & & & & \\
\hline & $\begin{array}{l}\text { Introduction to Secondary } \\
\text { Physics Education }\end{array}$ & 3 & & & & & & 3 & & & & \\
\hline & $\begin{array}{l}\text { Secondary Physics Lab and } \\
\text { Instruction Strategies }\end{array}$ & 2 & & & & & & 4 & & & & \\
\hline \multirow{9}{*}{$\begin{array}{l}\text { Teacher education } \\
\text { compulsory } \\
\text { Electives } \\
\text { (minimum } 2 \\
\text { credits) }\end{array}$} & $\begin{array}{l}\text { Physics Education Research } \\
\text { and Reform }\end{array}$ & 2 & & & & & & & & 3 & & \\
\hline & $\begin{array}{l}\text { Education Research in } \\
\text { Secondary Physics Labs }\end{array}$ & 2 & & & & & & & & $2+2$ & & \\
\hline & $\begin{array}{l}\text { Integration of Secondary } \\
\text { Physics Education and } \\
\text { Information Technology }\end{array}$ & 2 & & & & & & & & 3 & & \\
\hline & Physics Education Psychology & 2 & & & & & & & & 3 & & \\
\hline & $\begin{array}{l}\text { Seminar-Secondary } \\
\text { Physics Education }\end{array}$ & 2 & & & & & & 2 & & & & \\
\hline & $\begin{array}{l}\text { Scientific Methods and } \\
\text { Physics Education }\end{array}$ & 1 & & & & & & & & 1 & & \\
\hline & $\begin{array}{l}\text { History of Physics for } \\
\text { Secondary Education }\end{array}$ & 2 & & & & & & & & 2 & & \\
\hline & $\begin{array}{l}\text { Measurement and Quantitative } \\
\text { Evaluation in Physics } \\
\text { Education }\end{array}$ & 2 & & & & & & & & 2 & & \\
\hline & $\begin{array}{l}\text { Comparative Education } \\
\text { Research in Secondary } \\
\text { Schools }\end{array}$ & 1 & & & & & & 1 & & & & \\
\hline \multirow{2}{*}{$\begin{array}{l}\text { Professional ethics } \\
\text { and placement }\end{array}$} & Educational Ethics & 2 & $\checkmark$ & $\checkmark$ & $\checkmark$ & $\checkmark$ & $\checkmark$ & $\checkmark$ & & & & \\
\hline & School Placement & 11 & & & & & & & $\checkmark$ & & & \\
\hline \multirow{4}{*}{$\begin{array}{l}\text { Research and } \\
\text { thesis }\end{array}$} & Research projects & 4 & & & $\checkmark$ & $\checkmark$ & $\checkmark$ & $\checkmark$ & $\checkmark$ & $\checkmark$ & $\checkmark$ & \\
\hline & Research seminars I & 1 & & $\checkmark$ & & $\checkmark$ & & & & $\checkmark$ & & \\
\hline & Research seminars II & 1 & & & & $\checkmark$ & & $\checkmark$ & & $\checkmark$ & $\checkmark$ & \\
\hline & Thesis & 8 & & & & & & & $\checkmark$ & $\checkmark$ & & $\checkmark$ \\
\hline
\end{tabular}




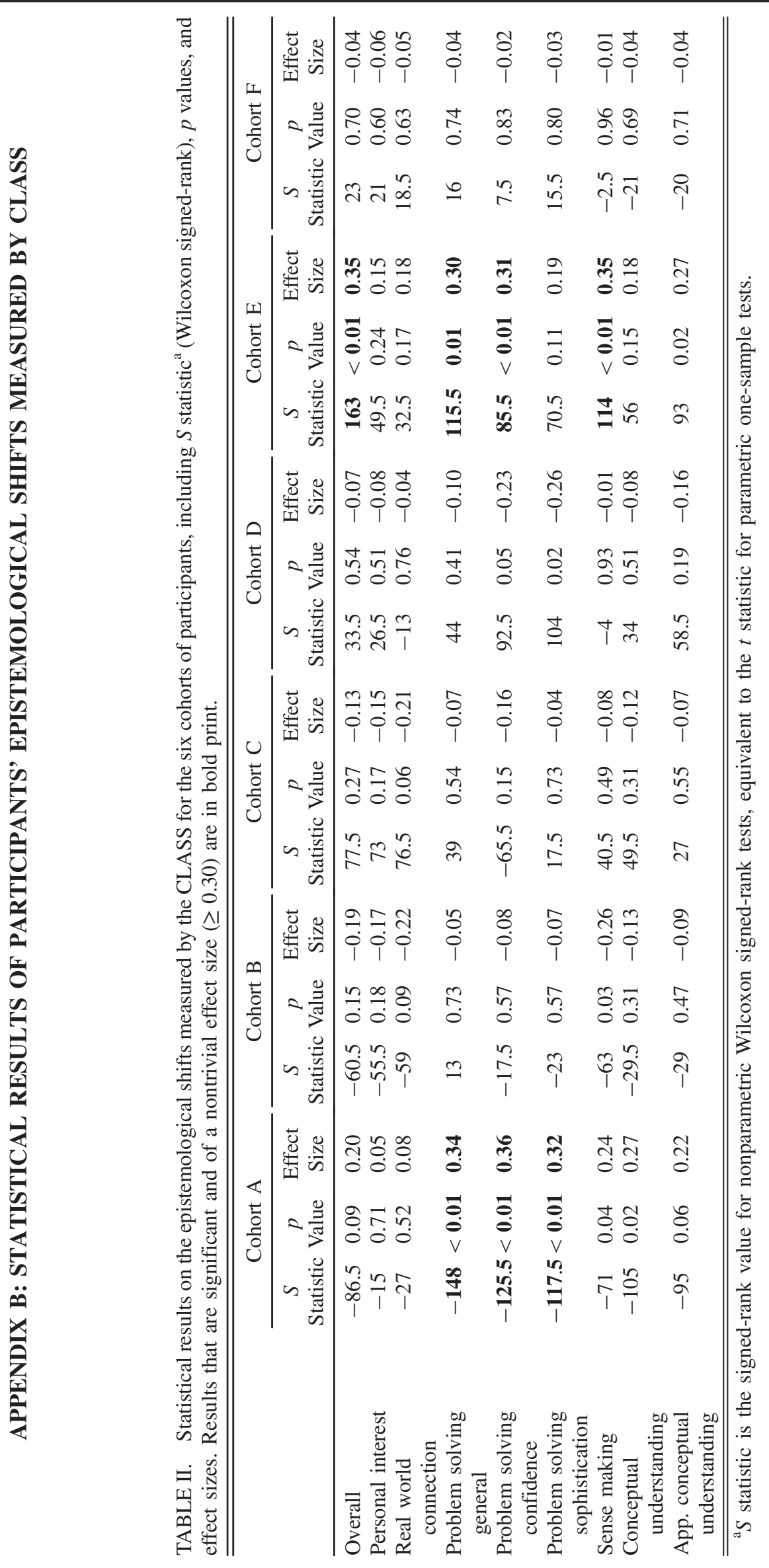


[1] D. Hammer and A. Elby, On the form of a personal epistemology, in Personal Epistemology: The Psychology of Belief about Knowledge and Knowing, edited by B. K. Hofer and P. R. Pintrich (Lawrence Erlbaum Associates, Mahwah, NJ, 2002), pp. 169-190.

[2] A. Elby, Helping physics students learn how to learn, Am. J. Phys. 69, S54 (2001).

[3] D. Hammer, Epistemological beliefs in introductory physics, Cognit. Instr. 12, 151 (1994).

[4] D. Hammer, Two approaches to learning physics, Phys. Teach. 27, 664 (1989).

[5] A. Elby, Another reason that physics students learn by rote, Am. J. Phys. 67, S52 (1999).

[6] L. Lising and A. Elby, The impact of epistemology on learning: A case study from introductory physics, Am. J. Phys. 73, 372 (2005).

[7] L. Ding, Verification of causal influences of reasoning skills and epistemology on physics conceptual learning, Phys. Rev. ST Phys. Educ. Res. 10, 023101 (2014).

[8] A. Madsen, S. B. McKagan, and S. C. Eleanor, How physics instruction impacts students' beliefs about learning physics: a meta-analysis of 24 studies, Phys. Rev. ST Phys. Educ. Res. 11, 010115 (2015).

[9] P. Zhang and L. Ding, Large-scale survey of Chinese precollege students' epistemological beliefs about physics: A progression or a regression?, Phys. Rev. ST Phys. Educ. Res. 9, 010110 (2013).

[10] W. K. Adams, K. K. Perkins, N. S. Podolefsky, M. Dubson, N. D. Finkelstein, and C.E. Wieman, New instrument for measuring student beliefs about physics and learning physics: The Colorado Learning Attitudes about Science Survey, Phys. Rev. ST Phys. Educ. Res. 2, 010101 (2006).

[11] P. Prinzie and P. Onghena, Cohort sequential design, in Encyclopedia of Statistics in Behavioral Science, edited by B. Everitt and D. Howell (John Wiley \& Sons, Hoboken, NJ, 2005), pp. 319-322.

[12] B. R. Johnson and A. J. Onwuegbuzie, Mixed methods research: a research paradigm whose time has come, Educ. Res. 33, 14 (2004).

[13] E. Gire and B. Jones, Characterizing the epistemological development of physics majors, Phys. Rev. ST Phys. Educ. Res. 5, 010103 (2009).

[14] S. Bates, R. Galloway, C. Loptson, and K. Slaughter, How attitudes and beliefs about physics change from high school to faculty, Phys. Rev. ST Phys. Educ. Res. 7, 020114 (2011).

[15] K. K. Perkins and M. Gratny, Who becomes a physics major? A long-term longitudinal study examining the roles of pre-college beliefs about physics and learning physics, interest, and academic achievement, AIP Conf. Proc. 1289, 253 (2010).

[16] K. Slaughter, S. Bates, and R. Galloway, A longitudinal study of the development of attitudes and beliefs towards physics, AIP Conf. Proc. 1413, 359 (2012).

[17] B. Hofer and P. Pintrich, The development of epistemological theories: Beliefs about knowledge and knowing and their relation to learning, Rev. Educ. Res. 67, 88 (1997).
[18] F. Abd-El-Khalick, Embedding nature of science instruction in preservice elementary science courses: Abandoning scientism, but..., J. Sci. Teach. Educ. 12, 215 (2001).

[19] W. A. Sandoval, Science education's need for a theory of epistemological development, Sci. Educ. 98, 383 (2014).

[20] M. Schommer, Effects of beliefs about the nature of knowledge on comprehension, J. Educ. Psychol. 82, 498 (1990).

[21] G. Qian and D. Alvermann, Role of epistemological beliefs and learned helplessness in secondary school students' learning science concepts from text, J. Educ. Psychol. 87, 282 (1995).

[22] A. Elby, Defining personal epistemology: A response to Hofer, and Pintrich (1997) and Sandoval (2005), J. Learn. Sci. 18, 138 (2009).

[23] W. A. Sandoval, Understanding students' practical epistemologies and their influence on learning through inquiry, Sci. Educ. 89, 634 (2005).

[24] W. A. Sandoval, In defense of clarity in the study of personal epistemology, J. Learn. Sci. 18, 150 (2009).

[25] E. F. Redish, R. N. Steinberg, and J. M. Saul, Student expectations in introductory physics, Am. J. Phys. 66, 212 (1998).

[26] C. Kalman, M. Sobhanzadeh, R. Thompson, A. Ibrahim, and $\mathrm{X}$. Wang, Combination of interventions can change students' epistemological beliefs, Phys. Rev. ST Phys. Educ. Res. 11, 020136 (2015).

[27] B. Hofer, Dimensionality and disciplinary differences in personal epistemology, Contemp. Educ. Psychol. 25, 378 (2000).

[28] B. Hofer, Domain specificity of personal epistemology: resolved questions, persist issues, new models, Int. J. Educ. Res. 45, 85 (2006).

[29] S. Carey, Conceptual Change in Childhood (MIT Press, Cambridge, MA, 1985).

[30] S. Carey and C. Smith, On understanding the nature of scientific knowledge, Educ. Psychol. 28, 235 (1993).

[31] A. Gopnik and H. M. Wellman, The theory theory, in Mapping the Mind, edited by L. A. Hirschfeld and S. A. Gelman (Cambridge University, New York, NY, 1994), pp. 257-293.

[32] S. Vosniadou, Mental models in conceptual development, in Model-Based Reasoning: Science, Technology, Values, edited by L. Magnani and N. Nersessian (Springer, New York, 2002), pp. 353-368.

[33] D. Hammer and A. Elby, Tapping Epistemological Resources for Learning Physics, J. Learn. Sci. 12, 53 (2003).

[34] D. Hammer, A. Elby, R. E. Scherr, and E. F. Redish, Resource, Framing, and Transfer, in Transfer of Learning from a Modern Multidisciplinary Perspective, edited by J. P. Mestre (Information Age Publishing, Greenwich, CT, 2005), pp. 89-120.

[35] A. Elby, Getting started with research on epistemologies, and expectations, in Getting Started in PER-Reviews in $P E R$, edited by C. Henderson and K. Harper (AAPT, College Park, MD, 2011), Vol. 2, p. 1.

[36] W. G. Perry, Forms of Ethical and Intellectual Development in the College Years: A Scheme (Rinehart and Winston, Holt, NY, 1970). 
[37] W. G. Perry, Cognitive and ethical growth: the making of meaning, in The Modern American College, edited by A. W. Chickering (Jossey-Bass, San Francisco, 1981), pp. 71-116.

[38] M. B. Baxter Magolda, The affective dimension of learning: faculty-student relationships that enhance intellectual development, Coll. Stud. J. 21, 46 (1986).

[39] M. B. Baxter Magolda, Knowing and Reasoning in College: Gender-Related Patterns in Students' Intellectual Development (Jossey-Bass, San Francisco, 1992).

[40] P. M. King and K.S. Kitchener, Developing Reflective Judgment: Understanding and Promoting Intellectual Growth and Critical Thinking in Adolescents and Adults (Jossey-Bass, San Francisco, 1994).

[41] D. Kuhn, The Skills of Argument (Cambridge University Press, Cambridge, England, 1991).

[42] E. Brewe, L. H. Kramer, and G. O'Brien, Modeling instruction: Positive attitudinal shifts in introductory physics measured with CLASS, Phys. Rev. ST Phys. Educ. Res. 5, 013102 (2009).

[43] E. Brewe, A. Traxler, J. d. 1. Garza, and L. H. Kramer, Extending positive CLASS results across multiple instructors and multiple classes of Modeling Instruction, Phys. Rev. ST Phys. Educ. Res. 9, 020116 (2013).

[44] B. Lindsey, L. Hsu, H. Sadaghiani, J. Taylor, and K. Cummings, Positive attitudinal shifts with the physics by inquiry curriculum across multiple implementations, Phys. Rev. ST Phys. Educ. Res. 8, 010102 (2012).
[45] M. Milner-Bolotin, T. Antimirova, A. Noack, and A. Petrov, Attitudes about science and conceptual physics learning in university introductory physics courses, Phys. Rev. ST Phys. Educ. Res. 7, 020107 (2011).

[46] V. K. Otero and K. Gray, Attitudinal gains across multiple universities using the Physics and Everyday Thinking curriculum, Phys. Rev. ST Phys. Educ. Res. 4, 020104 (2008).

[47] V. K. Otero, S. Pollock, and N. Finkelstein, A physics department's role in preparing physics teachers: The colorado learning assistant model, Am. J. Phys. 78, 1218 (2010).

[48] P. Kohl and V. Kuo, Chornicliing a successful secondary implementation of studio physics, Am. J. Phys. 80, 832 (2012).

[49] G. Kortemeyer, Correlations between student discussion behavior, attitudes, and learning, Phys. Rev. ST Phys. Educ. Res. 3, 010101 (2007).

[50] M. Hull, B. Lindsey, M. Archambault, K. Davey, and A. Liu, Unexpected attitudinal growth in a course combining reformed curricula, Phys. Rev. Phys. Educ. Res. 12, 010101 (2016).

[51] L. Ding and X. Liu, Getting started with quantitative methods in physics education research, in Getting Started in PER-Reviews in PER, edited by $\mathrm{C}$. Henderson and $\mathrm{K}$. Harper (AAPT, College Park, MD, 2012), Vol. 2, pp. 1-33.

[52] J. Pallant, SPSS Survival Manual: A Step By Step Guide to Data Analysis Using SPSS for Windows (Open University Press, Maidenhead, 2007), 3rd ed. 